
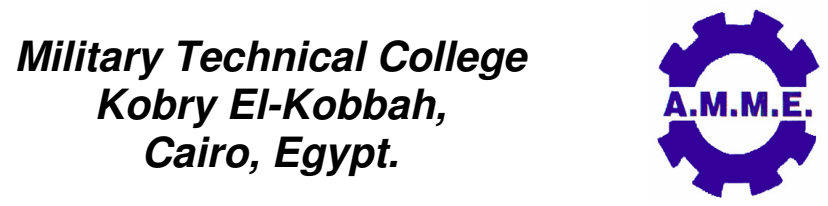
$15^{\text {th }}$ International Conference on Applied Mechanics and Mechanical Engineering.

\title{
NUMERICAL SIMULATION OF THE FLOW AROUND A LIGHT AIRCRAFT WING
}

\author{
E. E. Musa*, M. M. Abdulla* and O. A. Elsayed ${ }^{* \star}$
}

\begin{abstract}
This work aims to study and simulate the behavior of flow over SAFAT-01's wing using numerical simulation based on solving Reynolds's Averaged Navier-Stokes equations coupled with $\mathrm{K}-\omega$ turbulent model. The wing model is simple rectangular with elliptical ends. In the present work, aerodynamics characteristics and different flow phenomena were predicted at different design conditions (e.g. at different angles of attack) and at $\mathrm{Re}=5.2 \times 10^{6}$. The present study analysis the vortices which occur over wing and captured their effective regions at critical design conditions.

This study indicates that the maximum lift coefficient for SAFAT-01's wing is 1.44 occurred at stall angle of attack $12^{\circ}$, maximum lift to drag ratio (L/D) is 26 which occurs at $-4^{\circ}$, and the zero lift drag coefficient is 0.0142 . To validate this numerical simulation, a typical wing which found in Ref. [3] was analyzed, a comparison between predicted results and available results indicate that this numerical simulation has high ability for predicting the aerodynamics characteristics.
\end{abstract}

\section{KEY WORDS}

CFD, Wing design, Turbulence model, Turbulence intensity.

Assoc. professor, Dept. of Aeronautics, Karary University, Omdurman, Sudan.

** M. Sc. student, Dept. of Aeronautics, Airframe Design, Karary University, Omdurman, Sudan. Email: momahadi2007@hotmail.com.

*** Assistant Professor, Aeronautics Eng. Dpt., Sudan University of Science and Technology, Khartoum, Sudan. 


\section{NOMENCLATURE}

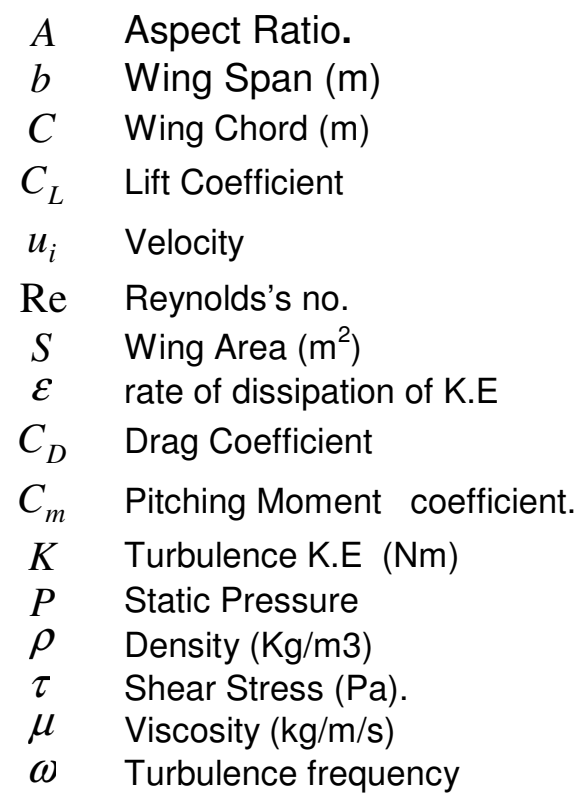

\section{INTRODUCTION}

Nowadays, CFD plays a great role in the preliminary a/c design but It has to be understood clearly, that CFD will never replace wind tunnel experimental work. In fact CFD give a strong support to analyze wind tunnel data in a complementary way, and making the result becomes more confidence in a new design before first flight.

Previous works for analyzing wings flow field using CFD as a tool include the work published by Shhin [1]. He solved Navier-Stokes coupled with K-omega turbulence model to calculate the aerodynamics data for different cases of Swept Wings. Wirachman et. al [2] discussed the aerodynamics behavior of a baseline design of a Blended Wing Body (BWB) at Mach 0.3 using both CFD and Wind Tunnel. Petra Aumann et. al [3] said that by the end of the 1980's, AIRBUS-D had put much validation effort into high level CFD technology. By the end of the 1990's, CFD itself was fully accepted and used within the aerodynamic design and data processes.

In the present work Reynolds Averaged Navier Stokes equations coupled with K- $\omega$ SST turbulence model are solved numerically to analyze and discuss the flow field around SAFAT-01's wing at different angles of attack. For purpose to validate this numerical simulation, a typical wing which found in Ref. [3] was analyzed. Comparing predicted results and available results indicate that, the current numerical simulation has high ability for predicting the aerodynamics characteristics.

\section{MODEL OF WING GEOMETRY}

Calculations were carried out on SAFAT01's wing and other wing used to validate the current numerical code. Figure1 shows the basic dimensions of these two wings. The general dimensional parameters of wing $\mathrm{w}-1$ and SAFAT-01's wing are shown in Table 1. 


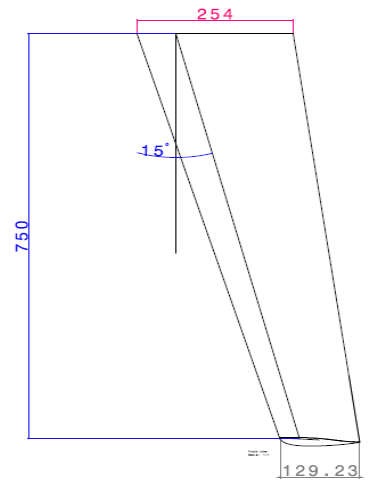

(a)

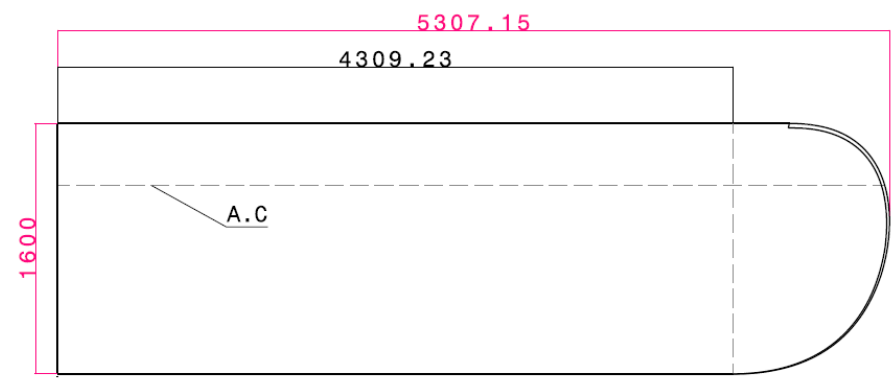

(b)

Fig.1. Geometry of models: (a) Wing w-1 $[1,19]$ and (b) SAFAT-01 wing (dimensions in $\mathrm{mm}$ ).

Table1. Geometrical data for wings.

\begin{tabular}{lcc}
\hline & Wing w-1 & SAFAT-01's Wing \\
\hline Area $\left(\mathbf{m}^{2}\right)$ & 0.14735 & 7.935 \\
Sweep angle (deg) & 15 & 0 \\
Taper Ratio & 0.5 & 1 \\
Span (m) & 1.5 & 10.6 \\
Aspect Ratio & 3.82 & 7.1 \\
Root Chord (m) & 0.254 & 1.6 \\
Incidence Angle (deg) & 0 & 2 \\
Twist angle at tip (deg) & 0 & 0 \\
Airfoil section & N/A & USA-35 b \\
\hline
\end{tabular}

\section{Governing Equations}

Navier-Stokes equations: These equations were employed in the following form $[4,5]$ :

$$
\frac{\partial \vec{q}}{\partial t}+\frac{\partial \vec{E}}{\partial x}+\frac{\partial \vec{F}}{\partial y}+\frac{\partial \vec{G}}{\partial z}=\frac{\partial \vec{R}}{\partial x}+\frac{\partial \vec{S}}{\partial y}+\frac{\partial \vec{T}}{\partial z}
$$

where

$$
\vec{q}=\left[\begin{array}{c}
\rho \\
\rho u \\
\rho v \\
\rho w
\end{array}\right] \quad \vec{E}=\left[\begin{array}{c}
\rho u \\
\rho u^{2}+p \\
\rho u v \\
\rho u w
\end{array}\right] \quad \vec{F}=\left[\begin{array}{c}
\rho v \\
\rho u v \\
\rho v^{2}+p \\
\rho v w
\end{array}\right] \quad \vec{G}=\left[\begin{array}{c}
\rho w \\
\rho u w \\
\rho v w \\
\rho w^{2}+p
\end{array}\right] \quad \vec{R}=\left[\begin{array}{c}
0 \\
\tau_{x x} \\
\tau_{x z} \\
\tau_{x z}
\end{array}\right] \quad \vec{S}=\left[\begin{array}{c}
0 \\
\tau_{y x} \\
\tau_{y y} \\
\tau_{y z}
\end{array}\right] \quad \vec{T}=\left[\begin{array}{c}
0 \\
\tau_{z x} \\
\tau_{z y} \\
\tau_{z z}
\end{array}\right]
$$

Turbulence model equation: Selection of turbulence model depends on type of grid i.e., structure or unstructured grid. Accordingly for the present simulation K-omega SST turbulent model was used for the purpose of turbulence closure. This model has 
wide spread popularity among CFD researchers. For more information about this model see F. R. Menter et.al [4, 9, 10]. He states that this model is more accurate than k-epsilon especially near wall layers, and for flows with moderate adverse pressure gradients. He developed SST scheme for aerospace applications as follows [4]:

$$
\begin{aligned}
& \frac{\partial \rho k}{\partial t}+\frac{\partial \rho u_{j} k}{\partial x_{i}}=P_{k}-\beta^{*} \rho \omega k+\frac{\partial}{\partial x_{j}}\left(\left(\mu+o_{k 1} \mu_{t}\right) \frac{\partial k}{\partial x_{j}}\right) \\
& \frac{\partial \rho \omega}{\partial t}+\frac{\partial \rho u_{j} \omega}{\partial x_{i}}=\gamma_{1} P_{\omega}-\beta_{1} \rho \omega^{2}+\frac{\partial}{\partial x_{j}}\left(\left(\mu+o_{\omega 1} \mu_{t}\right) \frac{\partial \omega}{\partial x_{j}}\right)
\end{aligned}
$$

Definition of the eddy-viscosity [4]:

$$
v_{t}=\frac{k}{\omega}
$$

Turbulent stress tensor $\tau_{i, j}$ is given by [4]:

$$
\tau_{i, j}=v_{t}\left(\frac{\partial u_{i}}{\partial x_{j}}+\frac{\partial u_{j}}{\partial x_{i}}\right)-\frac{2}{3} k \delta_{i j}
$$

The shear stress is calculated as follows [4]:

$$
\tau=\rho a_{1} k
$$

With the constant $a_{1}=0.3$. On the other hand, in two-equation models, the shearstress is computed from [4]:

$$
\tau=\mu_{t} \Omega
$$

Boundary Layer Consideration: Boundary layer is calculated based on Reynolds number, the following expression is defined by $[6,14]]$ :

$$
\operatorname{Re}=\frac{\rho_{\infty} V_{\infty} \bar{C}}{\mu_{\infty}}
$$

The boundary layer thickness is calculated by [14]:

$$
\delta=\frac{0.37 x}{\operatorname{Re}_{x}^{1 / 5}}
$$

Computational method: Present simulation used numerical solution based on control volume techniques to convert the governing equation to algebraic equations that can be solved numerically $[5,13]$. The diffusion terms in the governing equations were descritize using second order accurate central difference while the convection terms were descritized using second order upwind equations. These equations were solved using implicit pressure based solver. This algorithm is based on solving these equations sequentially (i.e. segregated from another) SIMPLE algorithm method [15] is used for the coupling between pressure and velocity and satisfying the mass and momentum conservation laws [16]. 
Second-order upwind scheme: A Taylor series analysis of the upwind scheme discussed above will show that it is accurate in first-order in space and time. The firstorder upwind improved by choosing a more accurate second-order upwind scheme, $u_{x}^{-}$in equation (9) is defined as [5]:

$$
u_{x}^{-}=\frac{3 u_{i}^{n}-4 u_{i-1}^{n}+u_{i-2}^{n}}{2 \Delta x}
$$

and $u_{x}^{+}$is defined as [5]:

$$
u_{x}^{+}=\frac{-u_{i+2}^{n}+4 u_{i+1}^{n}-3 u_{i}^{n}}{2 \Delta x}
$$

This scheme is less diffusive compared to the first-order accurate scheme and is called linear upwind differencing (LUD) scheme.

Convergence Criteria: In order to check the convergence the lift and drag forces were calculated and assume that when the calculated values fixed the solution is converged.

Boundary Conditions: A symmetric boundary condition is used for all flow quantities at the root of wing. For the purpose of generating high quality mesh, the computational domain was divided into three zones. The velocity components are prescribed at the inlet. The atmospheric pressure and constant modified turbulence viscosity are defined at outlet.

Calculation of lift and drag: The lift and drag coefficient are related to $X, Y$ and $Z$ forces coefficient as follows [7,13]:

$$
\begin{aligned}
& C_{L}=-C_{x} \sin (\alpha)+C_{y} \cos (\alpha) \\
& C_{D}=C_{x} \cos (\alpha)+C_{y} \sin (\alpha)
\end{aligned}
$$

Grid generation: As shown in Fig. 2, the computational structured mesh are used for wing w-1 while unstructured mesh are used for Safat01' wing. This mainly, due that, the geometry of Safat01' wing is complex. Information about number of nodes for each wing is given in Table 2.

\section{RESULTS AND DISCUSSIONS}

\section{CFD Code Validation}

For purpose to validate the present numerical simulation, the flow through Wing w-1 was calculated and compared with that results which found in Ref. [3]. Fig. 3 presents the comparison of lift coefficient which predicted using present numerical simulation with the experimental results. This figure shows a good agreement between the results predicted by the present numerical simulation with the experimental results. 


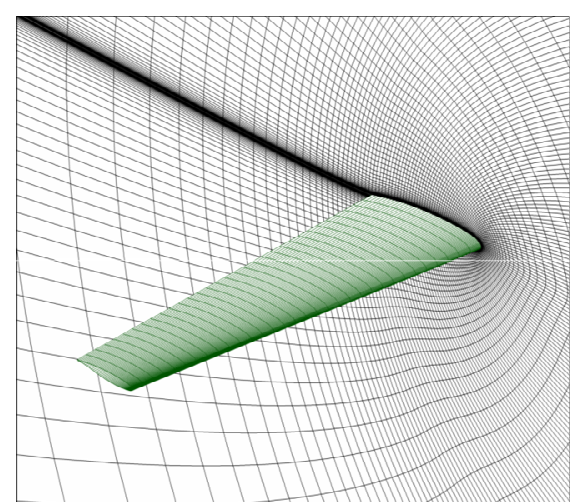

(a)

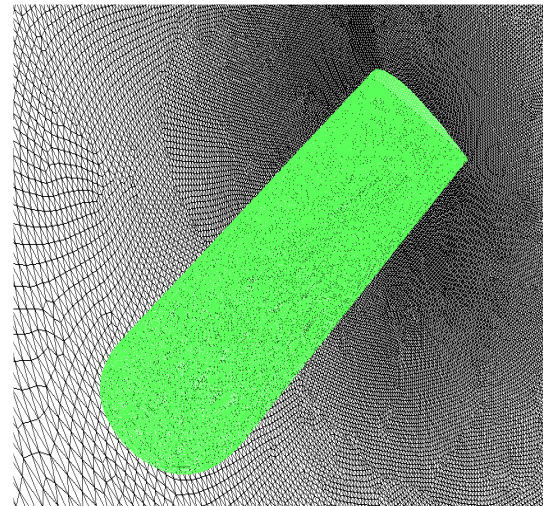

(b)

Fig.2. Grid Generation (a) Wing w-1[3], (b) SAFAT-01's wing.

Table 2. Number of grid elements for each wing

\begin{tabular}{ll}
\hline & Total No. of elements \\
\hline Wing W-1 & $3.9 \times 10^{6}$ \\
SAFAT-01's Wing & $2,516,699$ \\
\hline
\end{tabular}

Figure 4 shows the drag coefficient for wing $w-1$. This figure indicates a well agreement between present results and other results which found in Ref. [9], but present results and Tahran results who used Standard K-omega turbulence model, show a difference about 5 counts $\left(5 \times 10^{-3}\right)$. This difference is due to the assumptions of low turbulence level in free stream such that, a value of 0.13 in turbulence intensity is applied in solving this wing case.

Figure 5 shows the variation of pitching moment for wing W-1 with angle of attack. This figure indicates that the pitching moment is almost constant in the linear zone i.e. low angle of attack range (-6 deg 6 deg). This is mainly due to the assumption that the moment center is at quarter of chord which very close to the aerodynamics center. Also this figure indicates that the moment sign is minus due to positive wing camber so the wing alone is not stable.

Generally from previous analysis of wing $w-1$, we can say that the results of present numerical simulation show it has a good accuracy in predicting aerodynamics characteristics of lifting surface.

\section{Application of CFD Code to Safat01's Wing}

Figure 6 shows the relation between lift coefficient $C L$ and angle of attack $\alpha$ for SAFAT-01's wing in the range of $\alpha=-8^{\circ} \sim 14^{\circ}$. The curve of lift curves is linear in the region ( $\alpha=-8^{\circ}$ to $12^{\circ}$ ) but at the angle of attack higher than $12^{\circ}$ the trends become nonlinear. In the linear zone the lift coefficient increases as the angles of attack 
increase. In the nonlinear zone, the wing's lift curve is decreased at certain angles of attack (12 deg). The maximum $C_{L}=1.43$.

Figure 7 shows the relation between drag coefficient and lift coefficient, drag polar is a mathematical expression that relates the drag to some function of the lift coefficient. the curve line is polar nonlinear curve, by increasing lift coefficient i.e. increasing angle of attack the drag is increased, this is due to the presence of the induced drag.

Figure 8 shows the relation between moment coefficient and angle of attack, the moment center is considered in the $1 / 4$ chord, the moment is almost constant in the range of $\left(\alpha=-8^{\circ}\right.$ to $\left.4^{\circ}\right)$, but increasing $\alpha$ greater than $4^{\circ}$ lead to increase pitching moment, this is because the aerodynamics center of this airfoil is not coincide with the $1 / 4$ chord.

Figure 9 shows the curve of lift-to-drag ratio (L/D) as a function of angle of attack ( $\alpha$ ). It is noticed that the current CFD scheme gives the maximum value of $\mathrm{L} / \mathrm{D}=26$ at $\alpha=$ $-4^{\circ}$. Which indicate the best range and endurance of the SAFAT-01a/c.

Figures 10-a and 10-b illustrate the pressure contours in upper and lower surfaces captured in $\alpha=0$ (deg) of SAFAT-01's wing, we observe that the pressure in upper surface is lower than the pressure on lower surface due to the positive wing camber and the presence of wing incidence angle.

Figure 11-a and 11-b illustrate the pressure in upper and lower surfaces at $\alpha=10(\mathrm{deg})$, it is observed that the pressure in lower surface is higher than upper surface. Comparing Figs. $10 \mathrm{a}, \mathrm{b}$ with Figs $11 \mathrm{a}$, b, it is clear that the pressure difference between lower and upper surface increases by increasing angle of attack due to Increasing the angle of attack gives a larger lift from the upward component of pressure on the bottom of the wing. The lift force can be considered to be according to Newton's $3^{\text {rd }}$ law reaction force to the force exerted downward on the air by the wing. At higher angle of attack separated flow increases the drag dramatically and will stall the wing at $\alpha=12(\mathrm{deg})$.

Figure 12 shows the flow Pathlines colored by velocity magnitude at $\alpha=O(d e g)$, the flow is attached to the upper surface and no vortex is captured in the upper surface, the wing tip vortices is very weak and a little twist observed in the flow at the tip. Also this figure indicates that, the velocity magnitude in the upper surface is almost zero due to wall boundary conditions and the definition of the turbulent.

Figure13 shows the flow pathlines over the upper surface of wing at $\alpha=12(\mathrm{deg})$. This figure indicates an existence of vortex on upper surface and tip vortices. The vortices zones are captured by the pencil and zoomed as shown in fig.13. This figure reveals that, the separation occurs near wing root first and starts to extend spanwisely by increasing angle of attack. Due to vortices near the wing root trailing edge thus it is predicted that wing flap may not be effective at $\alpha>12(\mathrm{deg})$. Wing tip vortices have also high Kinetic Energy to swirl and rotate which increase the induced drag as a result. 


\section{CONCLUSION}

This paper contains Validation and analysis work. The validation work was carried out to prove that the results of this numerical simulation are acceptable and could be used for preliminary calculations of SAFAT-01 wing. The analysis work was done to report the aerodynamic performance of SAFAT-01 Wing intended to be capable for low subsonic operation. The 3-D model generated by CATIA became the basis of the CFD model for predicting the pressure and flow field around the wing, which subsequently develops to be the aerodynamic load. The CFD analysis carried at $\mathrm{V}=50 \mathrm{~m} / \mathrm{s}(180 \mathrm{~km} / \mathrm{hr})$. This velocity represents the loitering and the cruising phase of the mission profile. From the $C_{L}$ curves obtained from CFD coupled with visualization Flow Pathlines figures, it can be concluded that the maximum lift is occurred at $\alpha$ around $12^{\circ}-13^{\circ}$.

\section{Recommendation}

It is recommended to improve the wing to delay the flow separation. This can be done by changing the airfoil of the wing with more appropriate airfoil for low speed, and/or by increasing the surface area of the wing to generate more lift, and/or by twisting the wing to delay the separation.

It is strongly recommended to make an experimental test using Wind tunnel for the studied wing and compare CFD results with Wind tunnel results for further Validation and also conducting study of other aerodynamic parameters, including yaw and roll, taking into account difference Reynolds number.

\section{REFERENCES}

[1] Petra Aumann and Klaus Becker," MEGAFLOW for AIRBUS-D Applications and Requirements", DLR, (2009)

[2] Wirachman Wisnoe et. al, "Wind Tunnel Experiments and CFD Analysis of Blended Wing Body (BWB) Unmanned Aerial Vehicle (UAV) at Mach 0.1 and Mach 0.3" ,2009, Aerospace Sciences \& Aviation Technology ASAT-13-AE-13

[3] Pinar S., "Navier-Stokes Calculations Over Swept Wings", M. Sc. Thesis Middle East Technical University, September 2006

[4] Florian R. Menter, "Improved Two-Equation $k-\omega$ Turbulence Models for Aerodynamic Flows", NASA Technical Memorandum 103975.

[5] H.K. Versteeg and W. Malalasekera, "An Introduction to Computational Fluid Dynamics The Finite Volume Method", Pearson Education Limited, 2007, Harlow, England.

[6] Robert P. Little, "Flight Simulator Database Population from Wind-Tunnel and CFD Analysis of a Homebuilt Aircraft", M. Sc. Thesis, California Polytechnic State University, San Luis Obispo.

[7] FLUENT User Guide, Theoretical Manual, 2006, FLUENT Inc.

[8] H. Schlichting and K.Gersten, "Boundary Layer Theory", McGraw Hill, 2000, N.Y.

[9] F. R. Menter, M. Kuntz and R. Langtry, "Ten Years of Industrial Experience 
with the SST Turbulence Model", Turbulence, Heat and Mass Transfer 4, 2003.

[10] Menter, F.R. Zonal two-equation $k-\omega$ turbulence model for aerodynamic flows. AIAA Paper 1993-2906, 1993.

[11] AGARD Advisory Report No.303."A selection of Experimental Test Cases for the Validation of CFD Codes", Volume I, 1994.

[12] O. Brodersen and A. Sturmer, "Drag Prediction Of Engine-Airframe Interference Effects Using Unstructured Navier-Stokes Calculations", $19^{\text {th }}$ AIAA Applied Aerodynamics Conference, 2001.

[13] Courant, R., Isaacson, E., and Rees, M. (1952). "On the Solution of Nonlinear Hyperbolic Differential Equations by Finite Differences", Comm. Pure Appl. Math., 5, 243-255.

[14] John Anderson, Jr. "Fundamentals of Aerodynamics", $5^{\text {th }}$ edition, McGraw Hill, (2010), 981-1040.

[15] Patankar, S. V., "Numerical Heat Transfer and Fluid Flow", Taylor \& Francis.

[16] Hirsch, C., "Numerical Computation of Internal and External Flows". John Wiley \& Sons.

[17] T. J. Barth and D. Jespersen, "The design and application of upwind schemes on unstructured meshes" Technical Report AIAA-89-0366, AIAA 27th Aerospace Sciences Meeting, Reno, Nevada, (1989.)

[18] Zurriati M. Ali, et. al, "The Aerodynamics Performance of Blended Wing Body Baseline-II", (2011) IEEE

[19] AIAA $3^{\text {rd }}$ Drag Prediction Work Shop Presentations by Marviplis and Tahran, http://aaac.larc.nasa.gov/tsab/cfdlarc/aiaa-dpw/Workshop3/workshop3.html, Retrieved at $1^{\text {st }}$ March 2011.

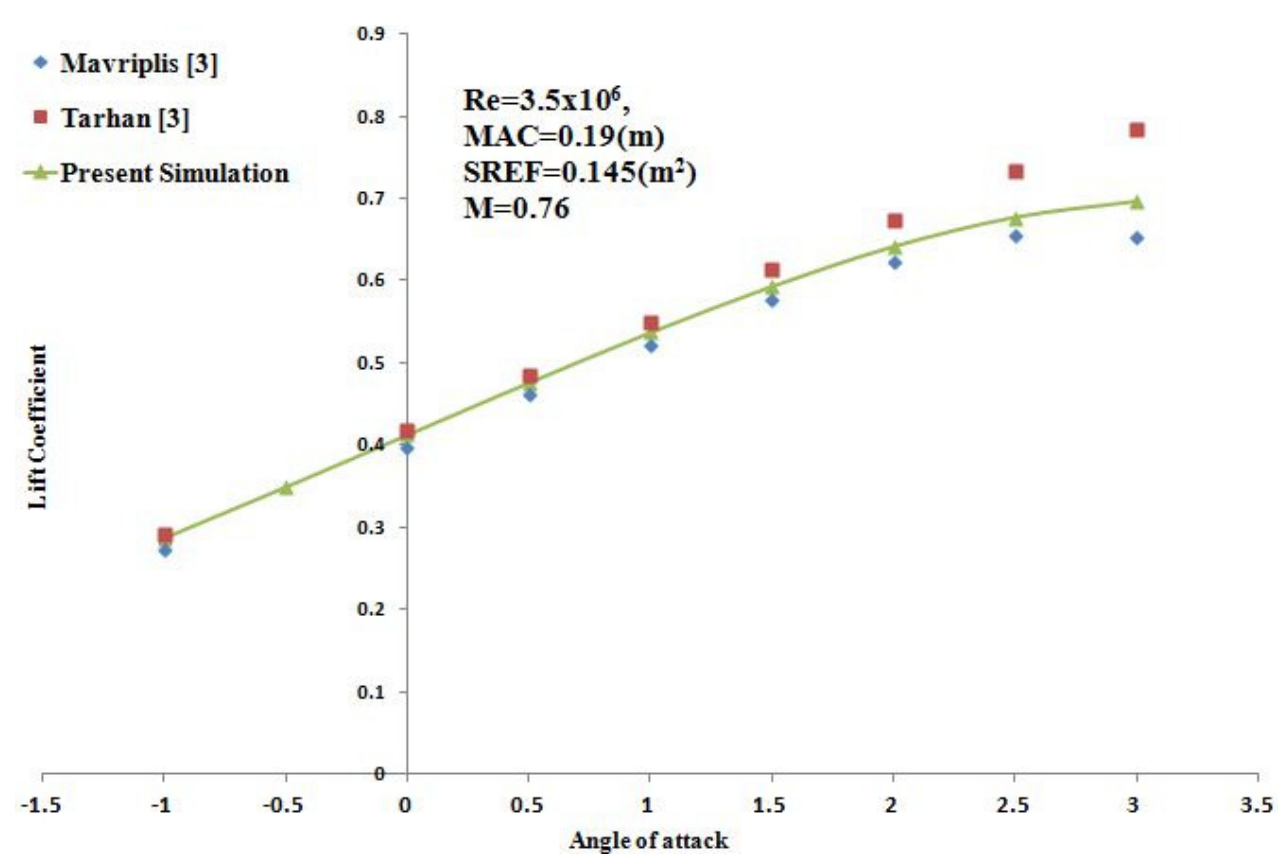

Fig.3. Lift coefficient Vs Angle of Attack (deg) for wing w-1. 


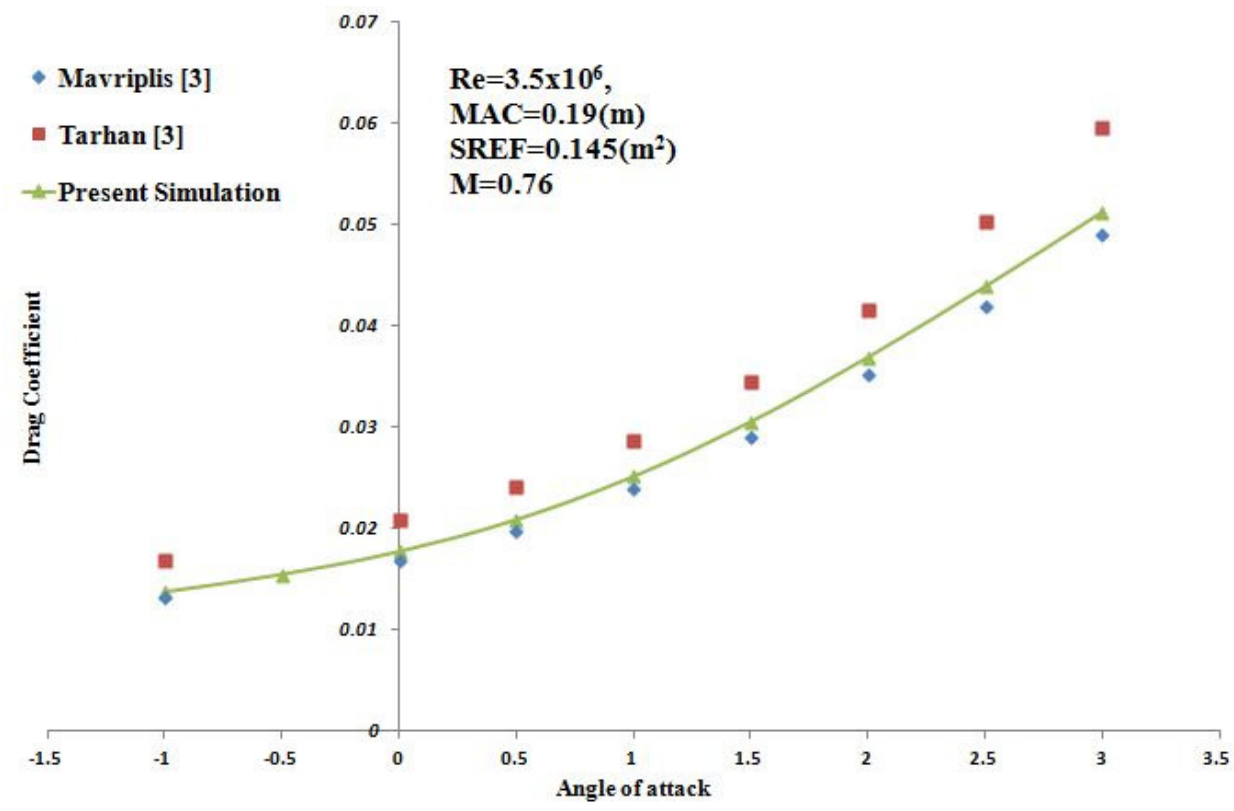

Fig. 4. Drag coefficient Vs Angle of Attack (deg) for wing w-1.

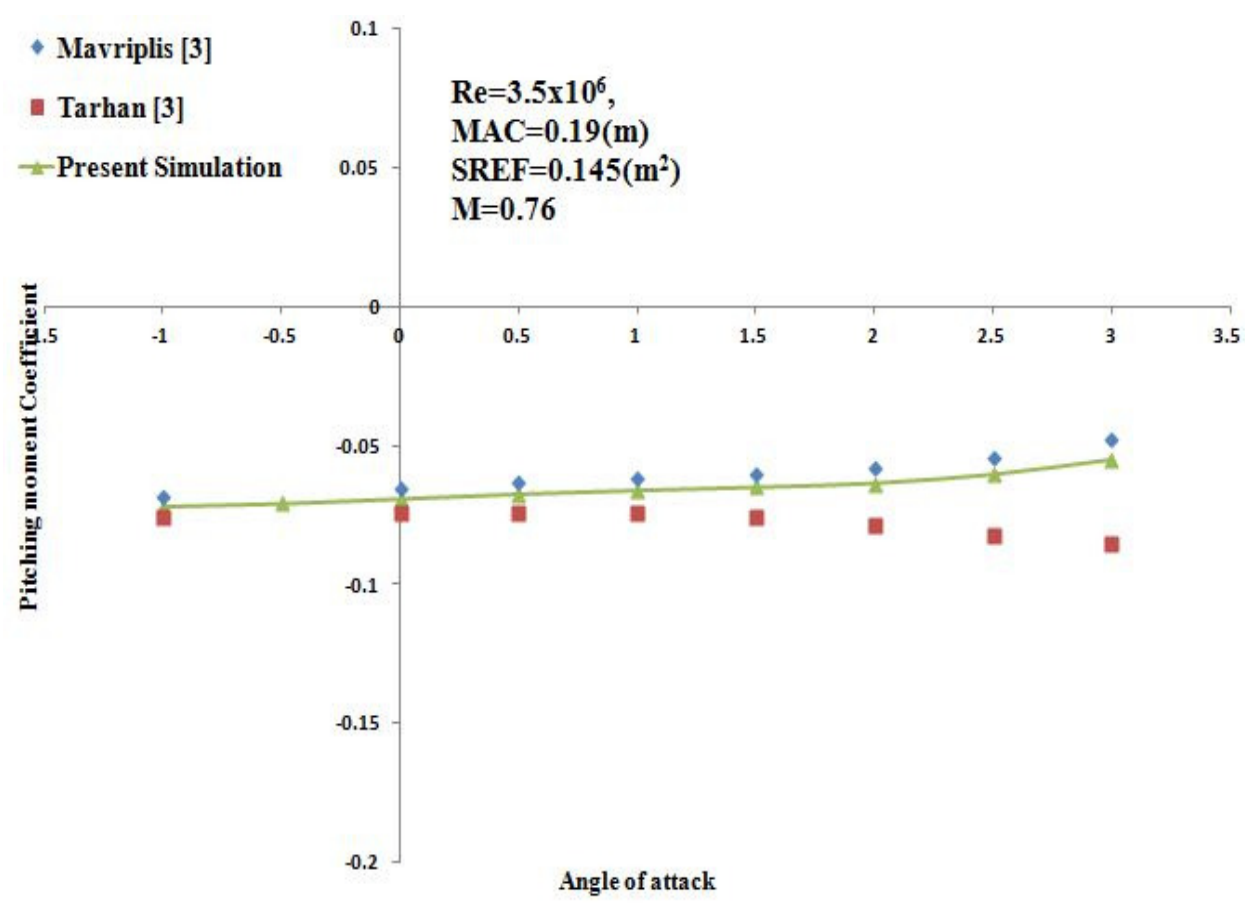

Fig. 5. Pitching moment coefficient about $1 / 4$ chords Vs Angle of Attack (deg) for W-1. 


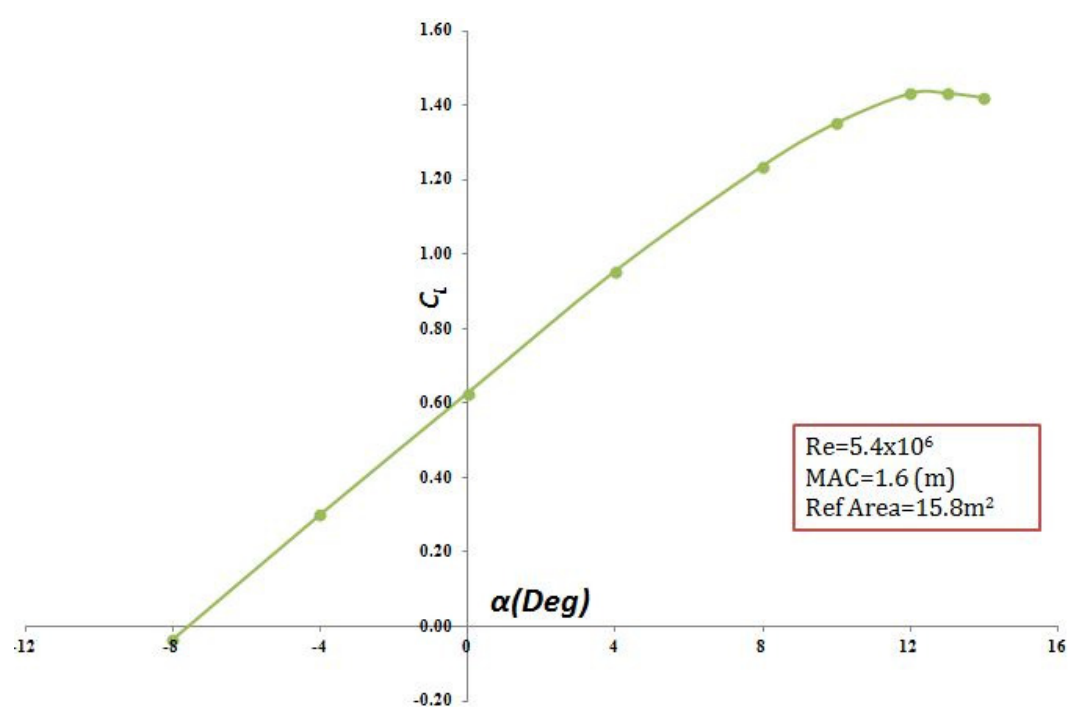

Fig. 6. Lift coefficient Vs. Angle of Attack (Deg) for SAFAT-01's wing.

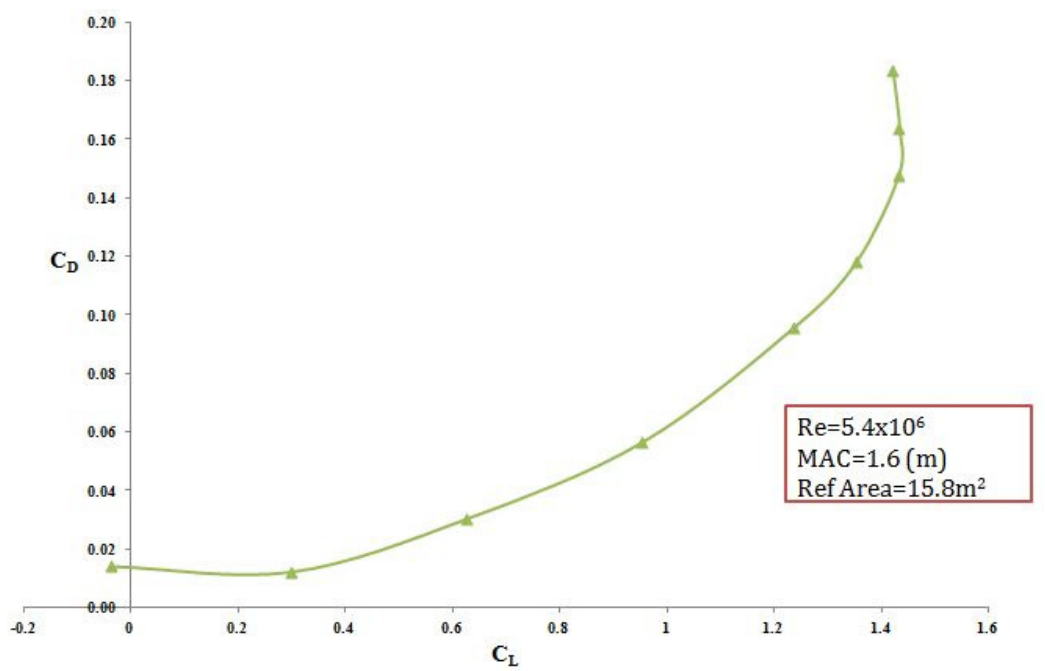

Fig. 7. Drag Polar for SAFAT-01.

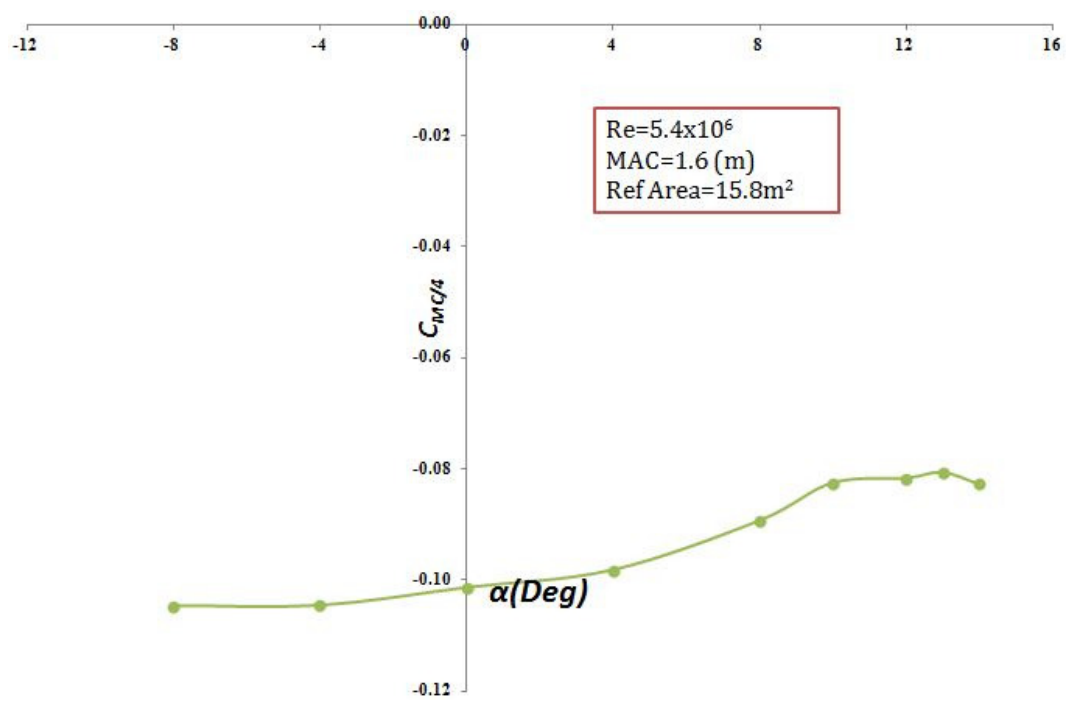

Fig. 8. moment coefficient $C_{m^{1 / 4}}$ Vs angle of attack for SAFAT-01's Wing. 


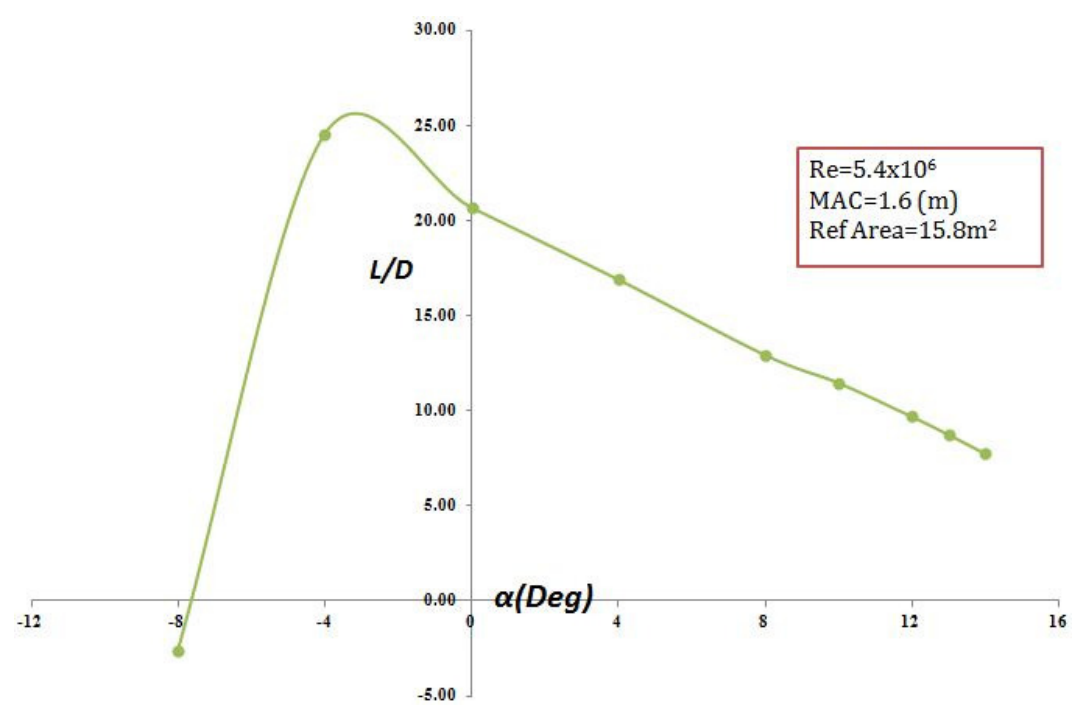

Fig. 9. Lift/Drag Vs Angle of Attack (deg).
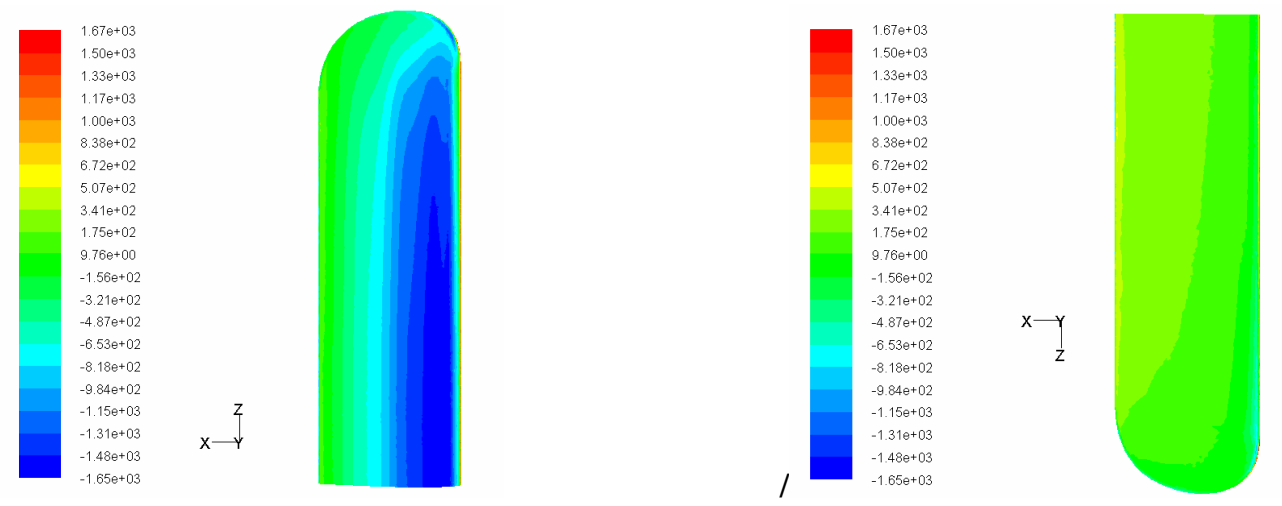

(a) Upper Surface

(b) lower surface

Fig.10. Pressure contours for safat01's wing at $\alpha=0$.

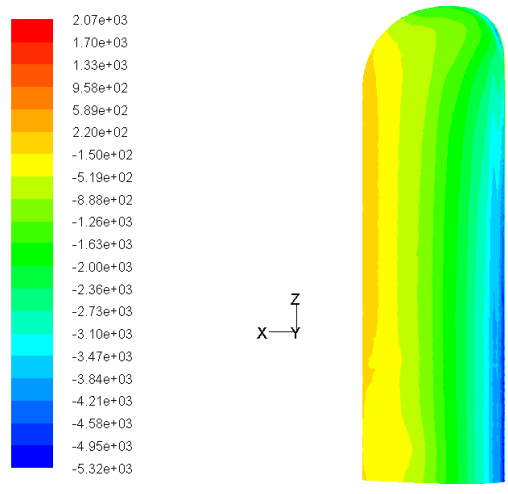

(a) Upper Surface

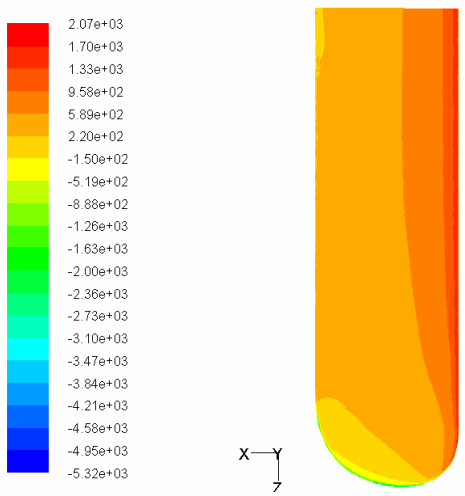

(b) lower surface

Fig. 11. Pressure contours for safat01's wing at $\alpha=10$. 


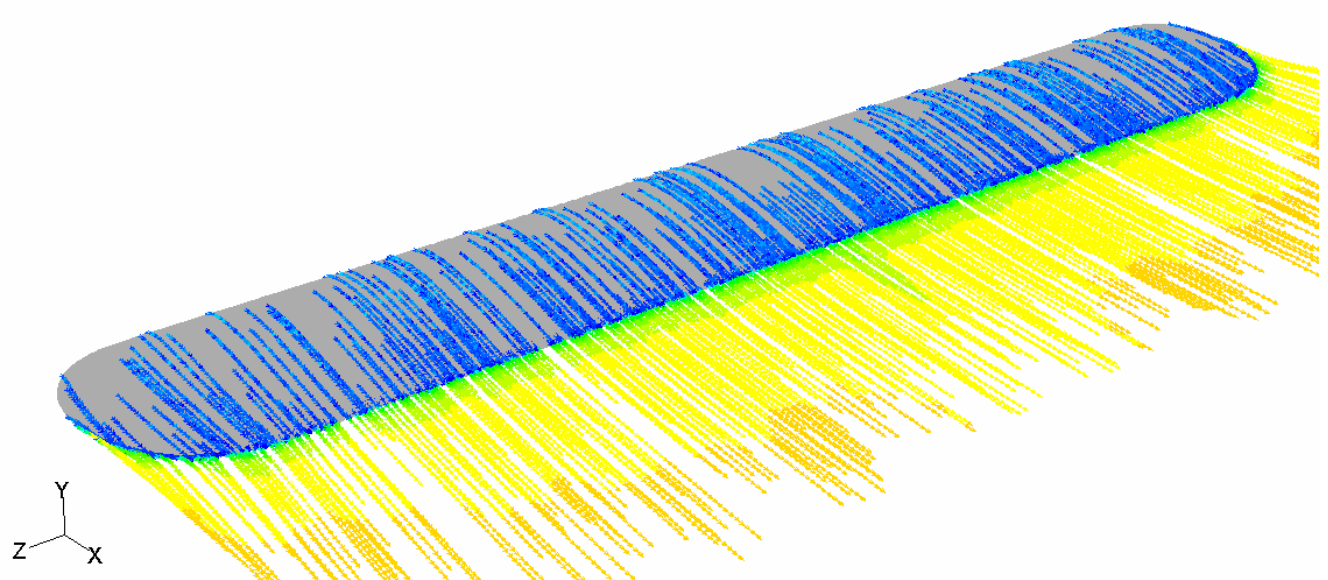

Fig.12. Flow Path lines colored by velocity magnitude at $\alpha=0$ (deg).

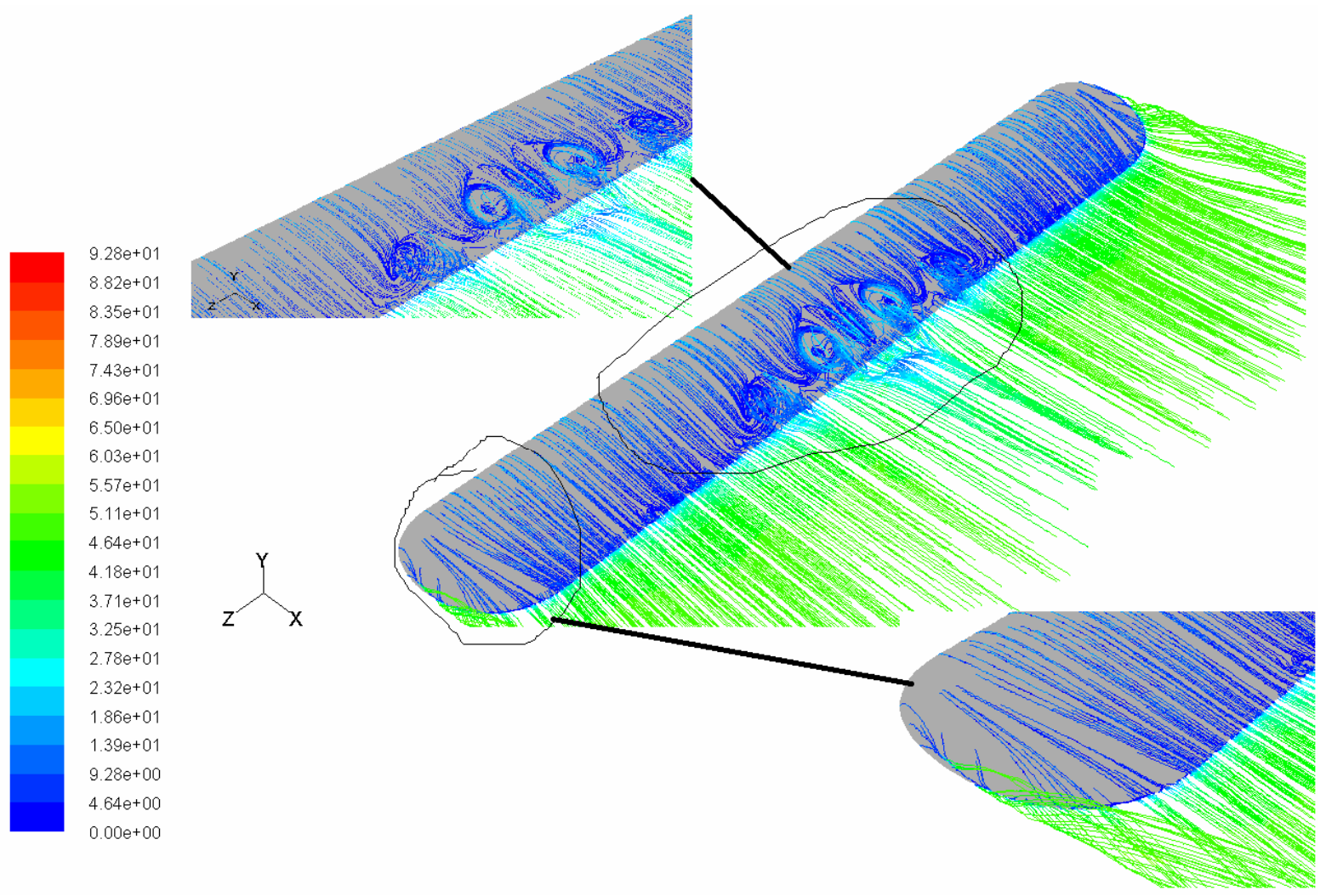

Fig.13. Flow vectors colored by velocity magnitude at $\alpha=12$ (deg). 